\title{
Radar observations of wind-shear splitting within evolving atmospheric Kelvin-Helmholtz
} billows

\author{
By D. CHAPMAN and K. A. BROWNING* \\ University of Reading, $U K$
}

(Received 17 October 1996; revised 27 January 1997)

\section{SUMMARY}

The high-resolution radar at Chilbolton was used to measure the velocity structure of large-amplitude KelvinHelmholtz billows within a precipitating warm-frontal zone. A deep layer of frontal shear was observed to split into thin layers of more concentrated shear displaying the characteristic braided structure previously reported within clear-air radar reflectivity patterns and attributed to a splitting of the thermal stratification. The billows were situated within a region of strong wind veer with height and they were orientated at right angles to the mean flow such that air parcels within them were tending to follow helical trajectories up the inclined frontal zone. Radar scans normal to the axes of the billows at different distances from their origin, close to the position of the surface warm front, provided an indication of the evolution of the split-shear structure.

\section{KEYWORDS: Aviation hazards Frontal zone Shear instability Vertical velocity}

\section{INTRODUCTION}

Stratified shear instability plays an important role in the atmosphere as Kelvin-Helmholtz billows induce vertical mixing. Whilst many observations of Kelvin-Helmholtz billows have been made using radar, few have shed light on the evolution of billows, or the effect they have on their environment. Those that have (Atlas et al. 1970; Browning and Watkins 1970) have described the behaviour of the thermal stratification rather than the shear, and it is not obvious that the two should necessarily evolve in the same way. In fact the distributions of shear obtained by James and Browning (1981) and derived from the study by Takahashi et al. (1993) show similar structures to the distribution of thermal stratification implied by clear-air echo studies, and this parallel behaviour between the shear and stratification is supported by numerical simulations by Scinocca (1995) who also discussed the outcome of the mixing in 'strong' and 'weak' cases. In this study the structure and evolution of the shear is shown to resemble that expected of the thermal stratification, and the evolution is traced beyond the collapse of the billows.

\section{NATURE OF THE DATA AND SYNOPTIC CONTEXT}

On the evening of 6 September 1995 a surface warm front approached and passed over southern Britain (see Fig. 1). Between 1500 and 2240 UTC reflectivity and Doppler data were obtained concurrently within an area of light rain and drizzle using the $3 \mathrm{GHz}$ radar at Chilbolton (approximately $80 \mathrm{~km}$ north of the Isle of Wight) with a range resolution of $300 \mathrm{~m}$ and an unusually high angular resolution of $0.25^{\circ}$ (Goddard et al.1994). Most of the data were in the form of range-height indicators (RHIs) (where the radar beam is scanned at different elevations in a fixed bearing (azimuth)-equivalent to a cross-section through the atmosphere in a vertical plane passing through the radar) at azimuth spacings of a few degrees. This article is concerned with the dynamical structure and evolution of Kelvin-Helmholtz billows within the strongly sheared frontal zone, and it is only the Doppler information from the radar that is used. The location of billows is shown in Fig. 1(b), and the shear responsible for their generation was orientated perpendicular to this cross-section.

\section{RESULTS}

Figure 2 shows a schematic plan view of the location of billows (as determined from velocity perturbations in RHIs such as that shown later in Fig. 4(a)) around the radar at 2100 and 2200 UTC. Vertical cross-sections of Doppler velocity were available in the region of the billows over two periods of time. Between 2010 (which was the time at which billows were first observed) and 2100 uTc observations were made south-west of the radar. From 2200 until 2240 UTC observations were made north-east of the radar. Between 2100 and 2200 uTc observations were made at ranges greater than $50 \mathrm{~km}$, out of the region in which billows occurred.

* Corresponding author: Joint Centre for Mesoscale Meteorology, Department of Meteorology, University of Reading, Whiteknights Road, PO Box 243, Reading, Berkshire RG6 6BB, UK. (The Joint Centre for Mesoscale Meteorology is supported by the Meteorological Office and the Department of Meteorology, University of Reading.) 


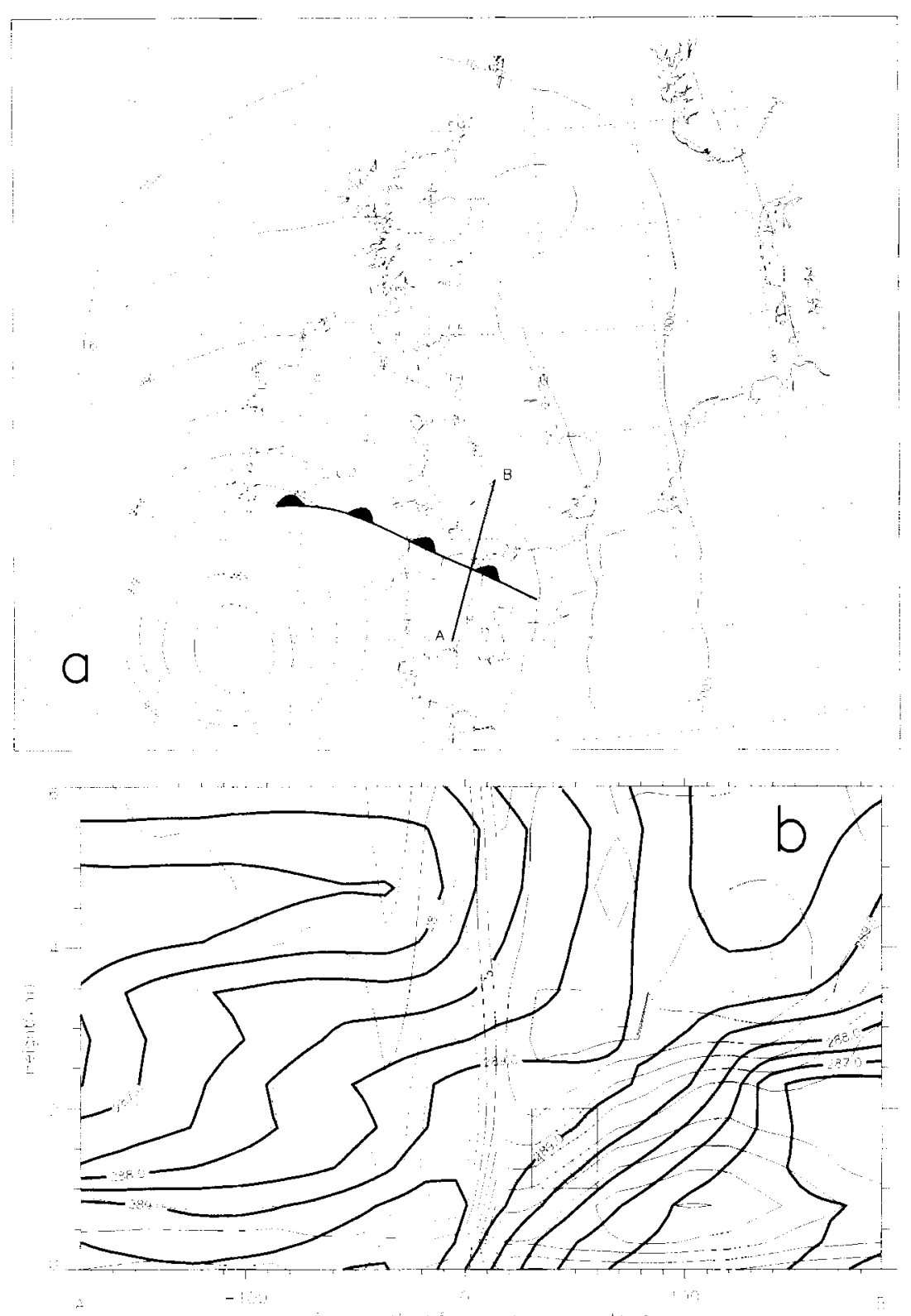

Figure 1. (a) Synoptic chart at 2100 UTC 6 September 1995 based on a $3 \mathrm{~h}$ forecast from the United Kingdom Meteorological Office Mesoscale Model showing the mean-sea-level pressure field $(\mathrm{mb})$ and the position of the surface warm front relevant to this study. (b) Vertical cross-section along line AB in (a). Bold contours are of wet-bulb potential temperature $(\mathrm{K})$. Lighter contours show the component of wind into the plane of this section (intervals of $1 \mathrm{~m} \mathrm{~s}^{-1}$ ); solid lines indicate positive values, dotted lines indicate negative values. In the study billows were observed in the region of strong shear between approximately 30 and $60 \mathrm{~km}$ north of the surface warm front, as indicated in the figure. 


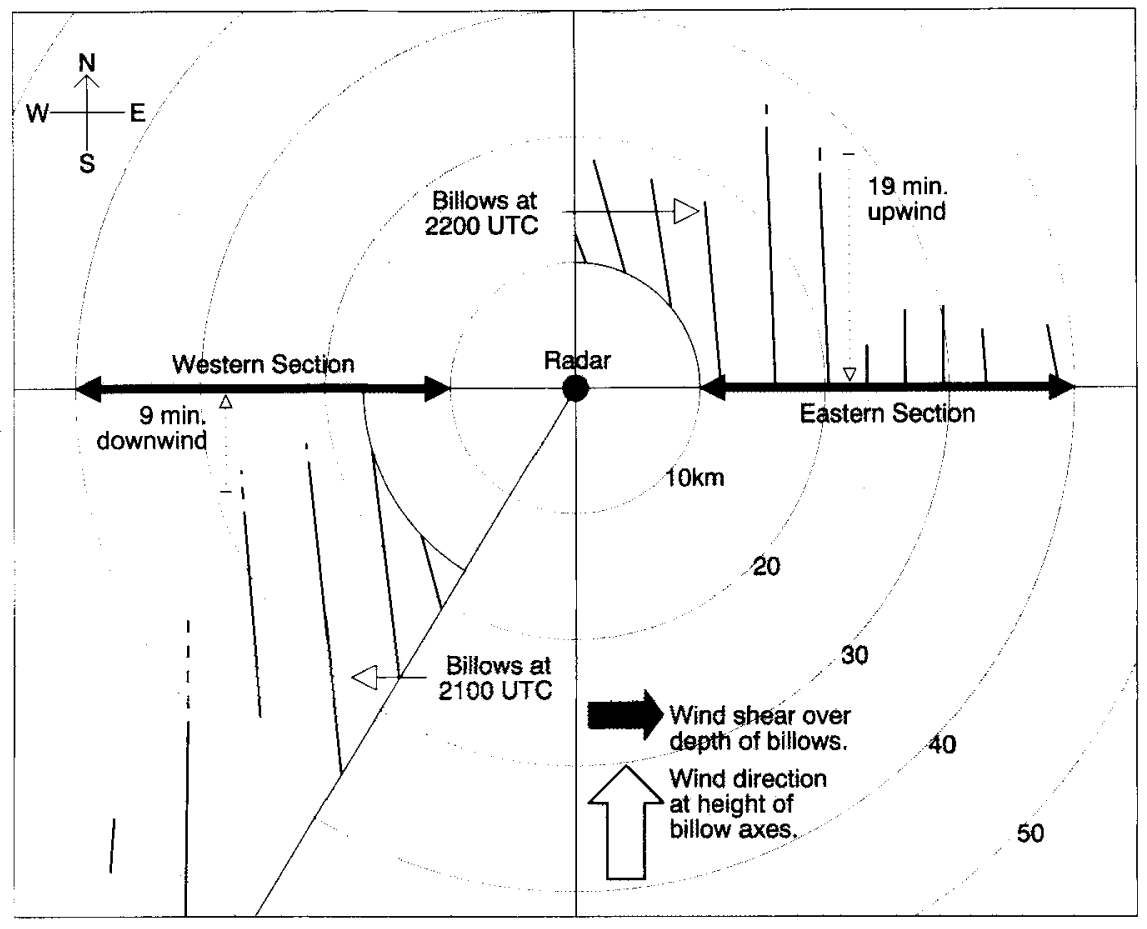

Figure 2. Schematic plan view showing location of billow crests south-west and north-east of Chilbolton radar at 2100 and 2200 UTC 6 September 1995 , respectively. No data were available in the shaded region. Locations of vertical sections described in the text and shown in Fig. 4 are indicated by bold arrows labelled Western Section and Eastern Section respectively. Broad arrows at foot of diagram show that there was a strong wind component along the billow axes, at right angles to the main component of shear. Thus the billows went through their life cycle from south to north; the dotted arrows show times of the western and eastern section in relation to the northern (decaying) ends of the billows.

The billows had a wavelength of around $5 \mathrm{~km}$ when observed to the west of the radar, and around $4 \mathrm{~km}$ to the east. Other properties such as amplitude and phase speed of the billows were also found to be very similar on both sides of the radar, and billows to the west of the radar are thought to have behaved in a broadly similar way to those to the east.

The surface warm front (as defined by sharp gradients in the wind field from radar observations) was moving northwards at approximately $10 \mathrm{~m} \mathrm{~s}^{-1}$. The patch of billows also appeared to have a northwards component of velocity approximately equal to this (although this could not be determined accurately), implying that the region containing billows was fixed relative to the surface front. A hodograph derived from radar data at 2210 uTc within the billows to the north-east of the radar is shown in Fig. 3 . This shows a layer of shear between 0.4 and $1.6 \mathrm{~km}$ in height within which there existed a strong west-east component of shear perpendicular to the billow axes. At the mean height of the billows the hodograph shows a southerly component of wind around $20 \mathrm{~m} \mathrm{~s}^{-1}$, so in a reference frame fixed relative to the front there was a southerly wind of around $10 \mathrm{~m} \mathrm{~s}^{-1}$ relative to the billow patch. As the billows developed at the southern end of the patch (presumably due to large-scale forcing in this region) they were advected northwards whilst continuing to grow; then they broke and decayed at the northern end of the patch. Thus successive west-east RHIs intersected the billows at different stages in their evolution as the patch moved northwards over a west-east line through the radar. The along-axis length of the billows appeared to be of the order of $30 \mathrm{~km}$, which gives a life-span of each billow of the order of 50 minutes (although the patch of billows existed for over 3 hours because of the continuous regeneration of the billows at their southern end).

Figures 4(c)-(f) show cross-sections of the vertical shear of the westerly component of the horizontal wind, derived from Doppler RHIs in a west-east direction such as that shown in Fig. 4(a). Figures 4(a)(d) show the active parts of the billows to the east of the radar, and Figs. 4(e) and (f) show the shear downwind of the billows to the west of the radar. Also shown in Fig. 4(a) is a mass-streamfunction derived 


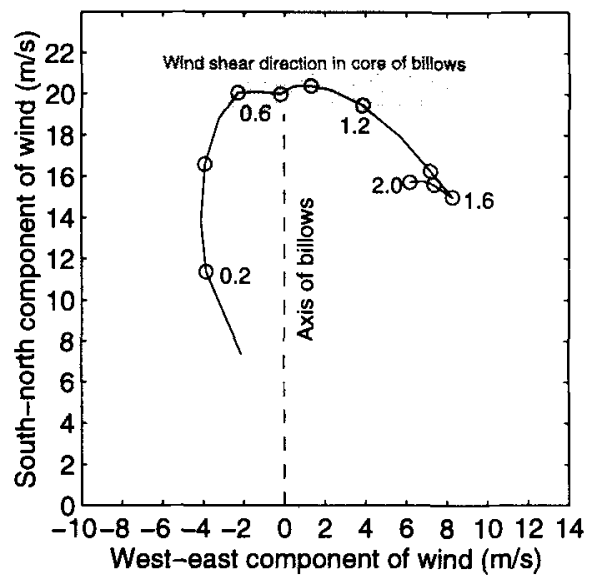

Figure 3. Hodograph showing wind velocity as a function of height within billows north-east of the Chilbolton radar at 2210 UTC 6 September 1995 . Values plotted at $0.2 \mathrm{~km}$ intervals.

by integrating the continuity equation upwards from the ground. The streamfunction is superimposed on the Doppler winds, indicating parcel trajectories projected onto the plane of the RHI (there was a mean southerly wind of $20 \mathrm{~m} \mathrm{~s}^{-1}$ into this plane at the level of the billows). This shows that air parcels within the billows (centred at a height of approximately $1 \mathrm{~km}$ ) followed trajectories that were approximately helical, with the main axis aligned in a south-north direction. The main assumption in deriving this streamfunction was that there was no variation of the south-north component of velocity along the length of the billows. There is clearly a strong correlation between the rolls shown by the streamfunction and the undulations in the Doppler data, indicating that the assumption was valid and that the billows were essentially 2dimensional in the region of the RHI. The same was true of a west-east RHI obtained at 2210 UTC (not shown). However, a similar manipulation of the Doppler data to give the streamfunction at 2200 UTC (also not shown) showed a poor correlation, indicating that at that time the air motion was 3-dimensional in the region of the RHI.

Figure 4(b) shows the vertical velocity (with the streamfunction from Fig. 4(a) superimposed) which was obtained from the Doppler velocity with the same 2-dimensional assumption that was used to derive the streamfunction. It can be seen that the billows induced vertical velocities as large as $\pm 3 \mathrm{~m} \mathrm{~s}^{-1}$.

Parts of the cross-sections of shear shown in Figs. 4(c)-(f) and a cross-section derived from the RHI at 2210 UTC were averaged (over approximately 14 to $24 \mathrm{~km}$ east of the radar in Figs. 4 (c) and (d), and 20 to $30 \mathrm{~km}$ west in Figs. 4(e) and (f)) to generate the mean-shear profiles shown in Figs. 5(a) and (b). The approximate location of the cross-section relative to the end of the billows that were averaged over was determined, and knowledge of the mean wind through the billows allowed the time of each profile within the lifecycle of the billows to be calculated. These varied from 19 to 25 minutes upwind of the region of collapse in Fig. 5(a) and from 9 to 19 minutes downwind of the region of collapse in Fig. 5(b).

\section{Discussion}

The sequence of shear profiles (Figs. 5(a) and (b)) shows that, within the billows (Fig. 5(a)), a single shear layer became split into two over a short period of time. Downwind of the billows (Fig. 5(b)) there existed a broad split-shear layer (solid line), though further downwind the split was less well defined (dotted line). The greater depth of the shear layer to the west of the radar (Fig. 5(b)) than to the east (Fig. 5(a)) is probably due to an imposed larger-scale variability in the depth of frontal shear. The detailed evolution of the structure of the shear layer can be observed in the relevant parts of Figs. $4(\mathrm{c})-(\mathrm{f})$.

Many observations of Kelvin-Helmholtz billows in the atmosphere have been made previously using radar to detect clear-air echoes from regions of high refractive-index variance occurring at airmass boundaries (Atlas et al. 1970; Browning and Watkins 1970; Browning 1971; Hardy et al. 1973. For a comprehensive review see Gossard (1990)). The distributions of reflectivity (and thus by implication the thermal stratification) obtained in this manner through billows are qualitatively similar to the distribution of shear shown in Figs. 4(c) and (d), indicating that in this case momentum was effectively mixed in the same way as the stratification, at least to a first approximation. 
a.
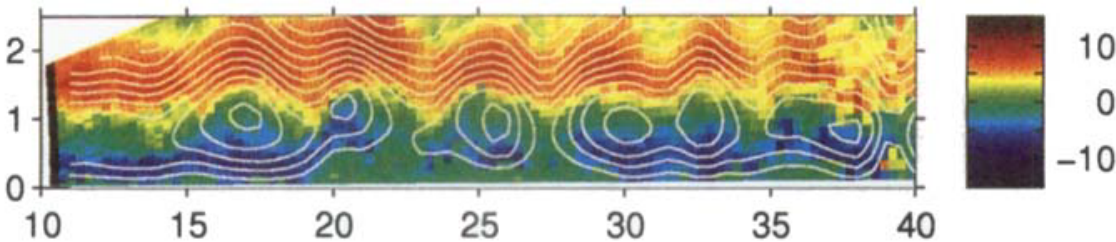

b
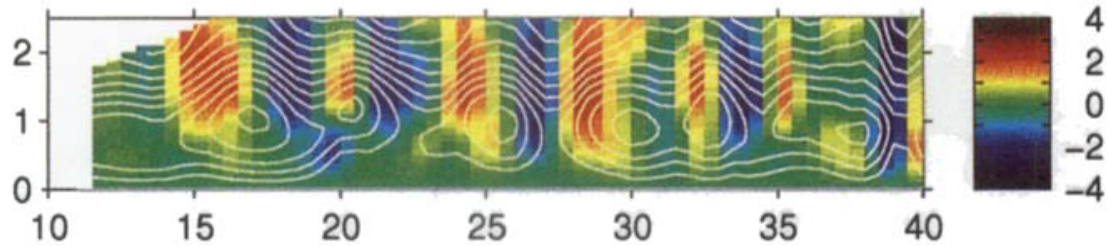

c.
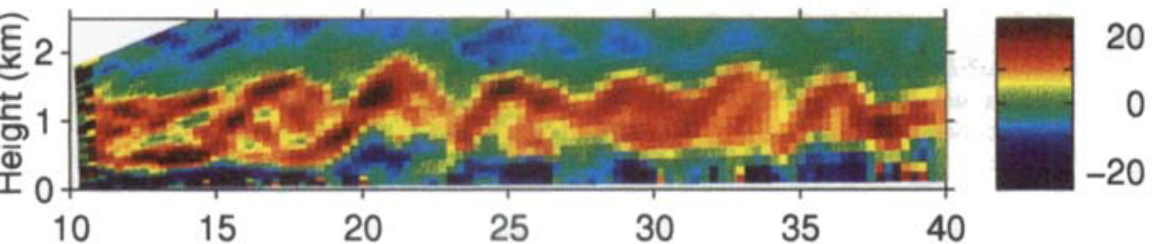

d.
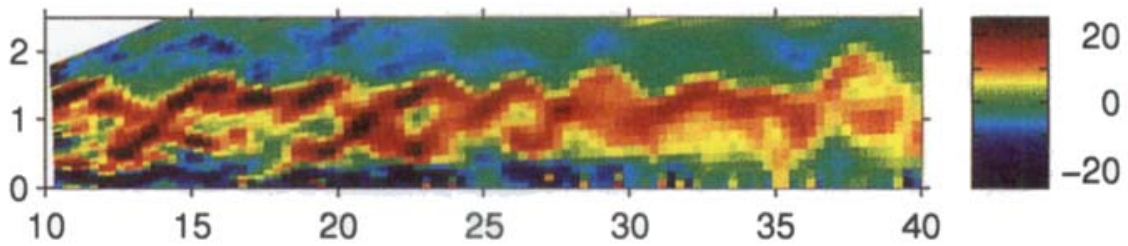

e.
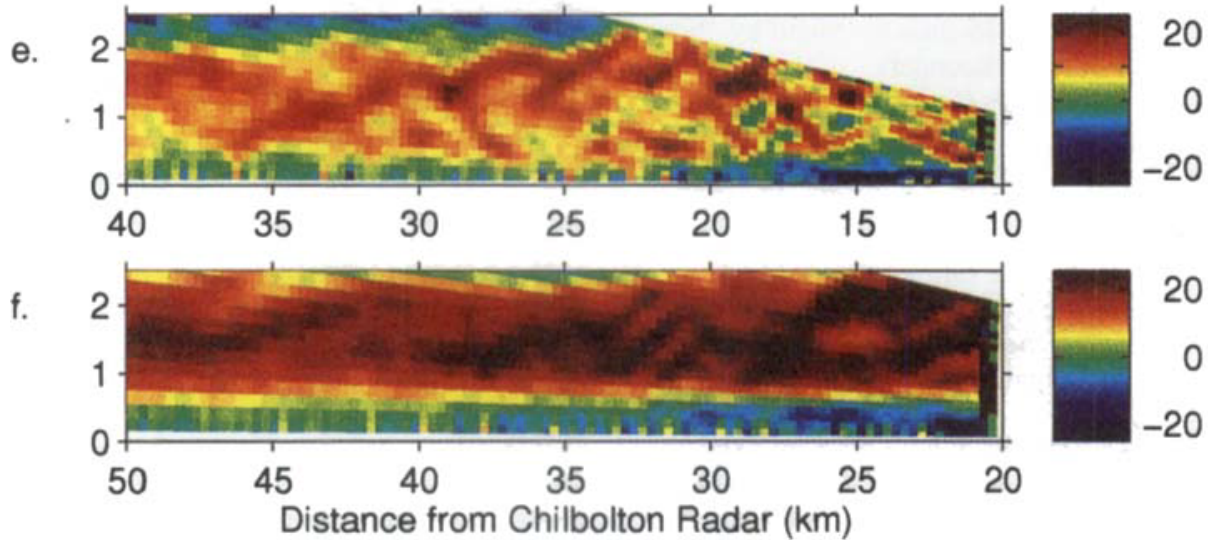

Figure 4. (a) Vertical west-east range-height indicator (RHI) cross-section of Doppler velocity, effectively giving westerly wind components ( $\mathrm{m} \mathrm{s}^{-1}$, blue to the left and red toward the right) at 2220 UTC 6 September 1995. Superimposed are contours of a mass-streamfunction (intervals of $1000 \mathrm{~kg} \mathrm{~m}^{-1} \mathrm{~s}^{-1}$ ) projected onto the plane of the RHI. (b) As (a), except shading shows vertical velocity $\left(\mathrm{m} \mathrm{s}^{-1}\right)$ at 2220 UTC. (c)-(f) Vertical west-east cross-sections of sheat $\left(\mathrm{m} \mathrm{s}^{-1} \mathrm{~km}^{-1}\right)$ derived from Doppler velocity RHIs at 2220, 2200, 2100 and 2020 UTC, respectively. (a)-(d) are eastern sections obtained upwind, and (e) and (f) are western sections obtained downwind of the region of billow collapse. 
(a)

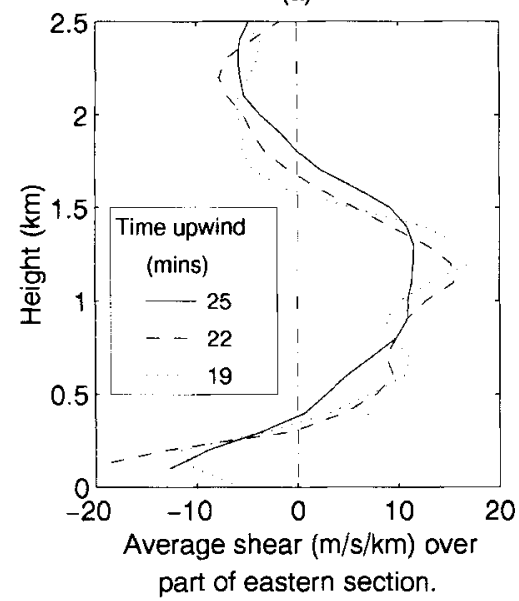

(b)

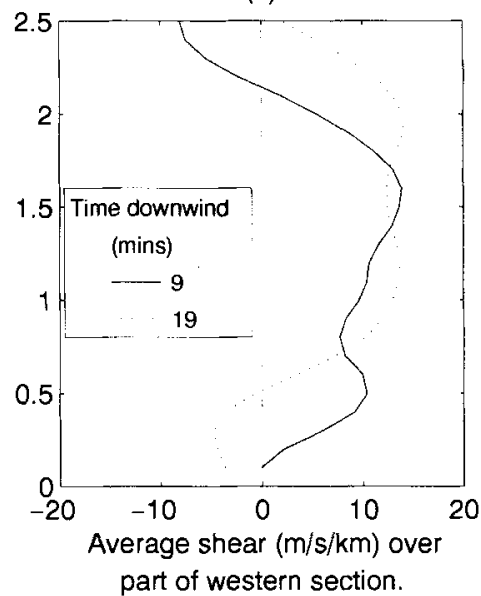

Figure 5. Profiles of shear $\left(\mathrm{m} \mathrm{s}^{-1} \mathrm{~km}^{-1}\right)$ averaged horizontally approximately at (a) 25, 22 and 19 minutes upwind and (b) 9 and 19 minutes downwind of the collapse of the billows. These profiles are derived from averages of shear cross-sections at times 2220, 2210, 2200, 2100 and 2020 UTC 6 September 1995, respectively.

The evolution of the shear layer in this case also resembles the evolution of the thermal stratification within billows of similar dimensions deduced from clear-air radar data by Browning and Watkins (1970). However, a difference is that they observed the stratification to become split into two long-lived layers downwind of the billows whereas the split shear was short-lived in the present case. The proximity of the frontal zone to the ground makes our case significantly different. It is likely that the strong south-north component of shear due to the boundary layer (Fig. 3) prevented a long-lived split from being sustained within the frontal zone. In view of the proximity of the boundary layer it is perhaps surprising that such well-formed billows were able to develop at all. Despite the south-north component of shear penetrating into the lower parts of the billows themselves, they had a life-span of around 50 minutes, compared with a life-span of around 15 minutes found by Browning and Watkins when there was no such potentially disruptive shear at the boundaries of the billows.

Numerical models (Sykes and Lewellen 1982; Klaasen and Peltier 1985; Scinocca 1995) and laboratory observations (Thorpe 1985) of Kelvin-Helmholtz billows have shown that their breakdown (under idealized conditions) is caused by convective instability forming vortices orientated perpendicular to the billows. Whilst the billows are still growing this instability is suppressed and they remain essentially 2-dimensional. Once the billows have reached their maximum amplitude the convective instability is allowed to grow, and the billows start to attain a 3-dimensional structure. The previously noted failure of the streamfunction calculation for the RHI at 2200 UTC (corresponding to the section within the billows closest to their northern end) may be due to the onset of this 3-dimensional structure, or it may be due to the onset of less organized 3-dimensional turbulence as the convectively unstable regions cause the wave to 'break'.

Kelvin-Helmholtz billows have been shown to be an important cause of clear-air turbulence (Browning et al. 1970), so at any altitude Kelvin-Helminoltz billows as strong as these could constitute an aviation hazard. However, in cases such as this the hazard is greatly increased due to the concentration of the moderate mean shear into regions of strong shear (up to around $25 \mathrm{~m} \mathrm{~s}^{-1} \mathrm{~km}^{-1}$ in this case) extending down to a few hundred metres above the ground. This would be most relevant during aircraft take-off and landing when the localized effects of the billows could lead to substantial underestimation of the low-altitude wind shear, even at airports where wind-profilers were in use.

\section{ACKNOWLEDGEMENTS}

We are grateful to Drs Anthony Illingworth and Mark Blackman for their part in the data acquisition, and thank the Radio Communications Research Unit at Rutherford Appleton Laboratory for access to the Chilbolton radar. We are also grateful to Peter Panagi for supplying the Mesoscale Model data. Daniel Chapman is supported by a studentship from the Natural Environment Research Council. 
Atlas, D., Metcalf, J. I., Richter, J. H. and

Gossard, E. E.

Browning, K. A.

Browning, K. A. and Watkins, C. D. 1970

Browning, K. A., Watkins, C. D. Starr, J. R. and McPherson, A

Goddard, J. W. F., Eastment, J. D. and Thurai, $M$.

Gossard, E. E.

Hardy, K. R., Reed, R. J. and Mather, G. K.

James, P. K. and Browning, K. A.

Klaassen, G. P. and Peltier, W. R.

Scinocca, J. F.

Sykes, R. I. and Lewellen, W. S.

Takahashi, N., Uyeda, H. and Kikuchi, K.

Thorpe, S. A.

\section{REFERENCES}

1970 The birth of CAT and microscale turbulence. J. Atmos. Sci., 27, 903-913

1971 Structure of the atmosphere in the vicinity of large-amplitude Kelvin-Helmholtz billows. Q.J. R. Meteorol. Soc., 97, 283299

Observations of clear-air turbulence by high-power radar. Nature, $227,260-263$

1970 Simultaneous measurements of clear air turbulence at the tropopause by high-power radar and instrumented aircraft. Nature, 228, 1065-1067

1994 The Chilbolton advanced meteorological radar: a tool for multidisciplinary research. Electronics and communications engineering J., 6. 77-86

1990 Radar research on the atmospheric boundary layer. Chapter 27a, pp. 477-527 in Radar in meteorology. Ed. D. Atlas. American Meteorological Society

1973 Observation of Kelvin-Helmholtz billows and their mesoscale environment by radar, instrumented aircraft, and a dense radiosonde network. Q.J. R. Meteorol. Soc., 99, 279-293

1981 An observational study of primary and secondary billows in the free atmosphere. Q. J. R. Meteorol. Soc., 107, 351-365

1985 The onset of turbulence in finite-amplitude Kelvin-Helmholtz billows. J. Flutd Mech., 155, 1-35

1995 The mixing of mass and momentum by Kelvin-Helmholtz billows. J. Atmos. Sci., 52, 2509-2530

1982 A numerical study of breaking Kelvin-Helmholtz billows using a Reynolds-stress turbulence closure model.J. Atmos. Sci., 39, $1506-1520$

1993 A Doppler radar observation on wave-like echos generated in a strong vertical shear. J. Meteorol. Soc. Japan, 71, 357-365

1985 Laboratory observations of secondary structures in KelvinHelmholtz billows and consequences for ocean mixing. Geophys. Astrophys. Fluid Dyn., 34, 175-199 